\title{
Expression of ezrin and moesin related to invasion, metastasis and prognosis of laryngeal squamous cell carcinoma
}

\author{
X. Wang, M. Liu and C.Y. Zhao \\ Department of Otorhinolaryngology \& Head and Neck Surgery, \\ Second Hospital Affiliated to Harbin Medical University, Harbin, China \\ Corresponding author: C.Y. Zhao \\ E-mail: chunyuanzhao@yeah.net
}

Genet. Mol. Res. 13 (3): 8002-8013 (2014)

Received August 28, 2013

Accepted January 16, 2014

Published September 29, 2014

DOI http://dx.doi.org/10.4238/2014.September.29.13

\begin{abstract}
We examined the expression of ezrin and moesin in laryngeal squamous cell carcinoma (LSCC) and their correlation with patient clinicopathological characteristics and overall survival. Immunohistochemical staining and reverse transcription-polymerase chain reaction (RT-PCR) for ezrin and moesin were applied to 60 carcinoma tissues, adjacent normal tissues, and 33 metastatic lymph nodes. Survival functions were estimated using the Kaplan-Meier method and compared by the log-rank test. RT-PCR demonstrated that the intensity ratios of ezrin and moesin to $\beta$-actin were higher in LSCC than in adjacent normal mucous membrane $(\mathrm{P}<0.05)$. Furthermore, intensity ratios were higher in cervical metastatic lymph nodes than in LSCC $(\mathrm{P}<0.05)$. Immunohistochemical staining showed that ezrin and moesin were well distributed in the cell membrane and cytoplasm. Expression was significantly different between LSCC and adjacent normal tissues $(\mathrm{P}<0.05)$; moreover, expression in the cervical metastatic lymph nodes was higher than in LSCC $(\mathrm{P}<0.05)$. Expression of ezrin and moesin was significantly related to clinical stage, $\mathrm{T}$ stage, and cervical lymph node metastasis $(\mathrm{P}<0.05)$, except that moesin showed
\end{abstract}


no significant relationship with clinical stage $(\mathrm{P}>0.05)$. Patients with negative ezrin and moesin expression had a significantly longer overall survival time compared to patients with moderate and intense ezrin and moesin expression $(\mathrm{P}<0.001, \mathrm{P}<0.05)$. Ezrin and moesin expression is related to LSCC invasion and metastasis, and may be important molecular markers for predicting prognosis and therapeutic targets in LSCC patients.

Key words: Laryngeal squamous cell carcinoma; Ezrin; Moesin; Metastasis; Prognosis

\section{INTRODUCTION}

Laryngeal carcinoma is one of the most common malignancies of the head and neck and has varying incidence and mortality rates worldwide. Laryngeal squamous cell carcinoma (LSCC) is the most common histology of laryngeal cancer, which has a high incidence, particularly in the northern region of China. Primary treatment strategies include surgery with radiotherapy and chemotherapy. However, patients often endure many serious side effects, tumor relapse, and metastasis.

The most common metastasis in laryngeal carcinoma is cervical lymph node metastasis. Multiple factors are involved in the regional relapse or distant metastasis after treatment. Identification of genes crucial for metastatic dispersion is important not only for understanding the molecular and cellular processes involved, but also for identifying potential new therapeutic targets. Ezrin and moesin belong to the ezrin-radixin-moesin family of proteins. They have similar structures and act as membrane-cytoskeleton linkers. Moreover, they have important regulatory roles in maintaining cell morphology, differentiation, motility, and cell-cell and cell-matrix adhesion (Vaheri et al., 1997), which contribute to overcoming challenges for the metastasis of tumor cells. Several studies have suggested that ezrin and moesin are associated with tumor invasion and metastasis in several types of cancer, such as nasopharyngeal carcinoma (Wang et al., 2011), oral cancer (Kobayashi et al., 2004), esophageal squamous carcinoma (Xie et al., 2009), colon cancer (Elzagheid et al., 2008), soft tissue sarcoma (Weng et al., 2005), and glioblastoma (Morales et al., 2010).

To elucidate the correlation of ezrin and moesin with clinicopathologic features, metastasis, and disease outcome in LSCC, we examined the expression of ezrin and moesin in LSCC and metastatic lymph nodes using reverse transcription (RT)-polymerase chain reaction (PCR) and immunohistochemistry staining. Ezrin and moesin may be new therapeutic targets for inhibiting metastasis of LSCC and predicting LSCC prognosis.

\section{MATERIAL AND METHODS}

\section{Materials}

All specimens were obtained from the Department of Otorhinolaryngology \& Head and Neck Surgery in the Second Hospital affiliated with Harbin Medical University of China between August 2005 and November 2006. Sixty laryngeal squamous carcinoma tissues, control 
tissues, and 33 metastatic cervical lymph nodes were confirmed by pathology. Control tissues were obtained from adjacent mucous membranes more than $1 \mathrm{~cm}$ away from the carcinoma tissues. None of the patients had received radiotherapy or chemotherapy. All specimens were stored in liquid nitrogen and fixed in 10\% formalin separately. Forty-five patients were males and 15 patients were females. The median age was 62.7 years (range, $45-78$ years). Eight patients received a second surgery. According to the tumor-node-metastasis stage, the number of patients in T1-T2 and T3-T4 was 23 and 47, respectively. Among these patients, 33 had cervical lymph node metastasis. According to the pathological differentiation degree, the number of high, moderate, and low differentiation squamous carcinoma was 38,15 , and 7 , respectively. The median follow-up time was 58.1 months (range, 26-83 months). Approval to review, analyze, and publish the data in this study was given by the Harbin Medical University Research Ethics Board.

\section{RT-PCR}

Total RNA was extracted from frozen-stored tissues with TRIzol reagent (Promega, Madison, WI, USA) in accordance with manufacturer instructions. RT was performed in a total volume of $20 \mu \mathrm{L}$ using $1 \mu \mathrm{g}$ total $\mathrm{RNA}, \mathrm{MgCl}_{2}$, oligo-dT primer, random primers, dNTPs, $10 \mathrm{X}$ buffer, recombinant RNase inhibitor, and AMV Reverse Transcriptase (Promega). RT was performed using a PCR amplifier at $42^{\circ} \mathrm{C}$ for $30 \mathrm{~min} ; 95^{\circ} \mathrm{C}$ for $5 \mathrm{~min} ; 4^{\circ} \mathrm{C}$ for 5 min. To normalize the results, $\beta$-actin was used as an internal control. PCR primers used for ezrin were as follows: forward primer (5'-GCGCTCTAAGGGTCTGCTCTG-3'); reverse primer (5'-TCTGGGTGATGTCCTGGATG-3'). According to the gene sequence of ezrin, a PCR product of $469 \mathrm{bp}$ was obtained. PCR primers used for moesin were as follows: forward primer (5'-TGTGAAGTCGTGGCCCGTTAG-3'); reverse primer (5'-GGGTAGAACTTGGCACGGAAC-3'), and a PCR product of 423 bp was obtained. For $\beta$-actin, the forward primer was 5'-CCCAGCACAATGAAGATCAAGATCAT-3' and the reverse primer was 5'-ATCTGCTGGAAGGTGGACAGCGA-3'. All primers were synthesized by Life Technologies (Carlsbad, CA, USA). PCR was performed using cDNA as a template. For ezrin, the PCR mixture was preheated at $94^{\circ} \mathrm{C}$ for $5 \mathrm{~min}$, followed by 35 cycles at $94^{\circ} \mathrm{C}$ for $45 \mathrm{~s}$ and $58^{\circ} \mathrm{C}$ for $30 \mathrm{~s}$, and extension at $72^{\circ} \mathrm{C}$ for $10 \mathrm{~min}$. For moesin and $\beta$-actin, the PCR mixture was preheated at $94^{\circ} \mathrm{C}$ for $5 \mathrm{~min}$, followed by 30 cycles at $94^{\circ} \mathrm{C}$ for $30 \mathrm{~s}, 55^{\circ} \mathrm{C}$ for $30 \mathrm{~s}$, and $72^{\circ} \mathrm{C}$ for $1 \mathrm{~min}$. Next, $3.0 \mu \mathrm{L}$ PCR product was applied to $2 \%$ agarose gel electrophoresis and then analyzed using a gel image analysis meter. The intensity ratio of ezrin and moesin to $\beta$-actin was scored.

\section{Immunohistochemical staining}

Specimens were fixed in $10 \%$ formalin, dehydrated using standard procedures, and then embedded in paraffin. Three continuous $4-\mu \mathrm{m}$ thick sections were used for hematoxylin and eosin (HE) staining to confirm the diagnosis and immunohistochemistry to detect ezrin and moesin proteins separately. The sections were adhered to 3-aminopropyltriethoxysilanecoated microscope slides and baked at $60^{\circ} \mathrm{C}$ for $30 \mathrm{~min}$. Sections were dehydrated, followed by blocking endogenous peroxidase activity in $3 \% \mathrm{H}_{2} \mathrm{O}_{2}$ (10 min at room temperature). The slides were incubated with mouse anti-human ezrin monoclonal antibody (dilution 1:75) and mouse anti-human moesin monoclonal antibody (dilution 1:75) in $0.1 \mathrm{M}$ phosphate-buffered 
saline (PBS, pH 7.4) overnight at $4^{\circ} \mathrm{C}$. Negative controls included PBS rather than primary antibody. Immunohistochemical staining was performed according to the SP kit instructions (ZhongShan Company, Beijing, China). Antigens were visualized using diaminobenzadine. Subsequently, the slides were counterstained by hematoxylin, dehydrated, and mounted. Tissue histology was contrasted by HE staining.

Ezrin and moesin were stained brown in the cytoplasm. Ezrin was linearly distributed inside the cytomembrane and as brown particles in the cytoplasm. According to the intensity of staining and positive cells based on the classification criteria of Mathew et al. (1996), each case was classified as follows: - (negative); + (moderate staining) less than 50\% positive cells or faint staining; ++ (intense staining) more than $50 \%$ positive cells and dark staining. All sections were evaluated independently by 2 investigators who had no prior knowledge of the patients' clinical information. When the opinions of the 2 evaluators differed, agreement was reached through discussion.

\section{Statistical analysis}

All statistical analyses were performed using the SPSS 13.0 software (SPSS, Inc., Chicago, IL, USA). Differences in the intensity ratio of RT-PCR were analyzed by using the Student $t$-test. The chi-square test was applied to analyze differences in the enumeration data of immuohistochemistry in LSCC tissues, metastatic lymph nodes, and adjacent normal tissues. Correlations between the expression of ezrin, moesin, and clinical factors were also analyzed by using the chi-square test. Overall survival time was measured from the date of diagnosis to either the date of death as a result of any cause or the date of last follow-up. Survival functions were estimated based on the Kaplan-Meier method and compared using the log-rank test.

\section{RESULTS}

\section{RNA extraction}

The absorbance of total RNA was measured using an ultraviolet (UV) spectrophotometer. The ratio of $A_{260}$ to $A_{280}$ values was used as the measure of RNA purity, and was in the range of 1.8-2.1. After denaturing agarose electrophoresis, the gel was visualized on a UV transilluminator. The $28 \mathrm{~S}$ and $18 \mathrm{~S}$ ribosomal RNA bands produced were fairly sharp and intense.

\section{RT-PCR}

The length of the objective gene segments of ezrin and moesin were 459 and $423 \mathrm{bp}$, respectively (Figures 1 and 2). The intensity ratios of ezrin $(0.6257 \pm 0.1028)$ and moesin $(0.5894 \pm 0.0453)$ to $\beta$-actin were higher in laryngeal carcinoma than in the normal mucous membrane $(0.0932 \pm 0.0314$ and $0.0918 \pm 0.0258$, respectively); the differences were significant $(\mathrm{P}<0.05)$ (Figure 3). Furthermore, their intensity ratios were both higher in the neck metastatic lymph node group $(0.7855 \pm 0.0897$ and $0.8024 \pm 0.0955$, respectively) than in the laryngeal carcinoma group $(\mathrm{P}<0.05)$. Expression of $\beta$-actin was consistent in the experimental and control groups. 


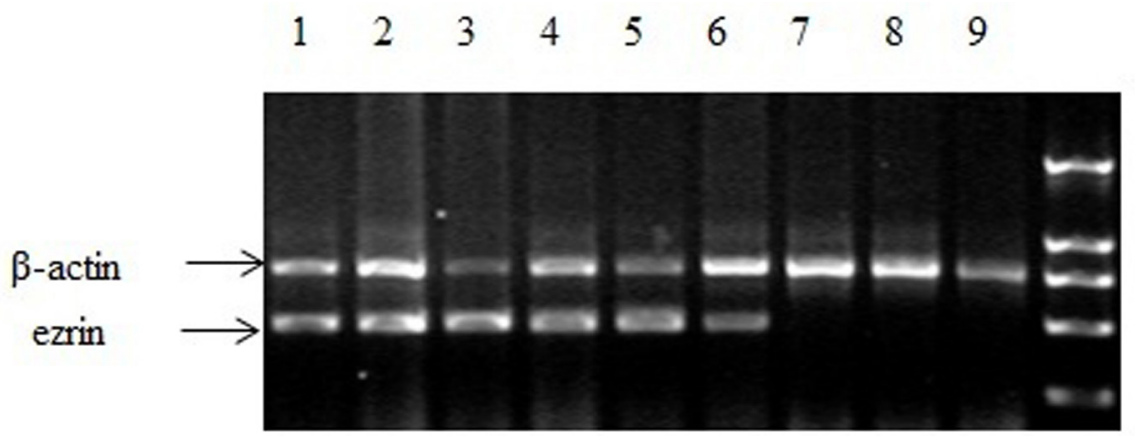

Figure 1. Expression of ezrin in laryngeal squamous cell carcinoma (LSCC) by RT-PCR. Lanes 1-6 = LSCC; lanes $7-9=$ control group.

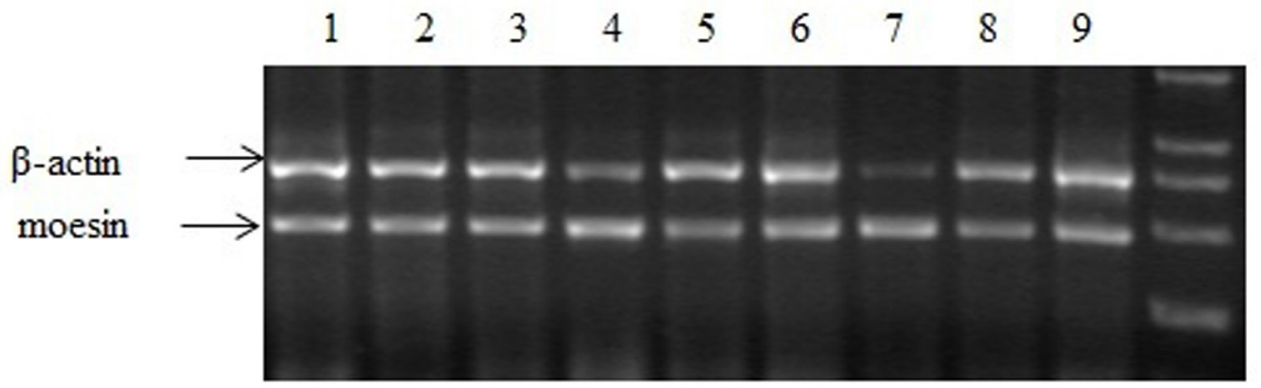

Figure 2. Expression of moesin in laryngeal squamous cell carcinoma (LSCC) by RT-PCR. Lanes 1-9 = LSCC.

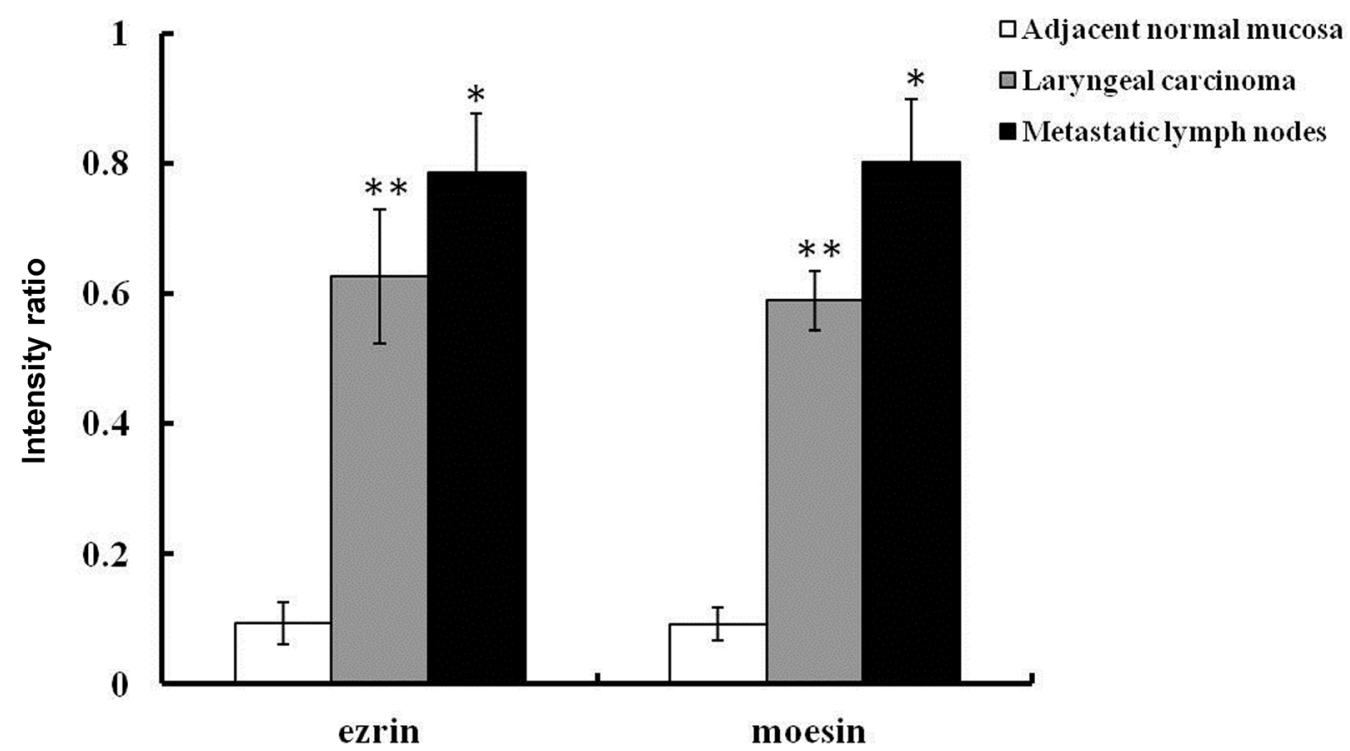

Figure 3. mRNA expression of ezrin and moesin by RT-PCR. $* * \mathrm{P}<0.05$ laryngeal carcinoma $v s$ adjacent normal mucosa. $* \mathrm{P}<0.05$ laryngeal carcinoma $v s$ metastatic lymph nodes. 


\section{Immunohistochemical staining}

Ezrin and moesin were well distributed in the cell membrane and the cytoplasm and appeared as a brown-yellow color (Figure 4). Expression of ezrin and moesin in the laryngeal carcinoma group was higher than that in the control group $(\mathrm{P}<0.01)$; moreover, their expression in cervical metastatic lymph nodes was higher than that in the laryngeal carcinoma group $(\mathrm{P}<0.01)$ (Figures 5 and 6). There were significant differences between the 2 groups. As shown in Table 1, ezrin and moesin expression showed no significant correlation with gender, age, tobacco smoking degree, and histological differentiation $(\mathrm{P}>0.05)$. However, their expression was significantly related to clinical stage, $\mathrm{T}$ stage, and cervical lymph node metastasis $(\mathrm{P}<0.05)$, except that moesin had no significant relationship with clinical stage $(\mathrm{P}>0.05)$.

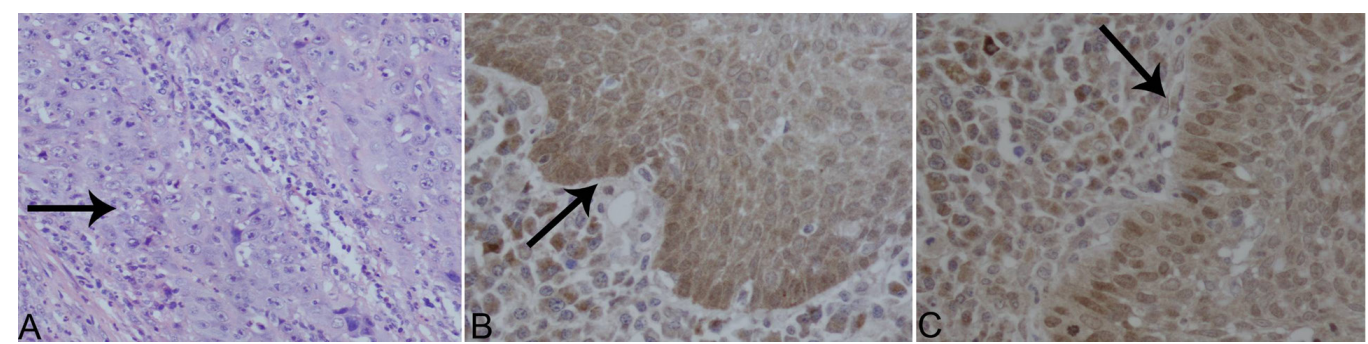

Figure 4. Immunohistochemical staining of ezrin and moesin in laryngeal squamous cell carcinoma (LSCC). A. HE staining of LSCC; B. ezrin in LSCC; C. moesin in LSCC.

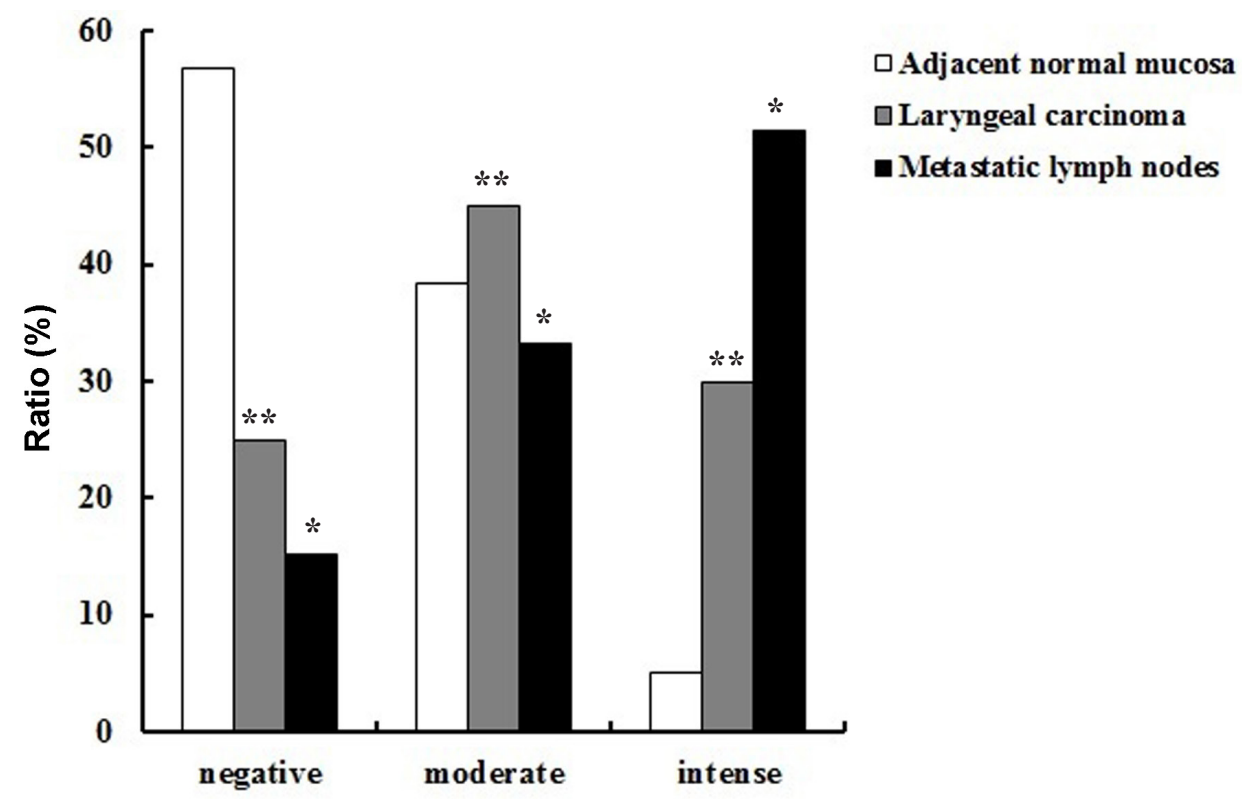

Figure 5. Expression of ezrin in laryngeal squamous cell carcinoma and cervical metastatic lymph nodes by immunohistochemical staining. $* * \mathrm{P}<0.01$ laryngeal carcinoma $v s$ adjacent normal mucosa. $* \mathrm{P}<0.01$ laryngeal carcinoma $v s$ metastatic lymph nodes. 


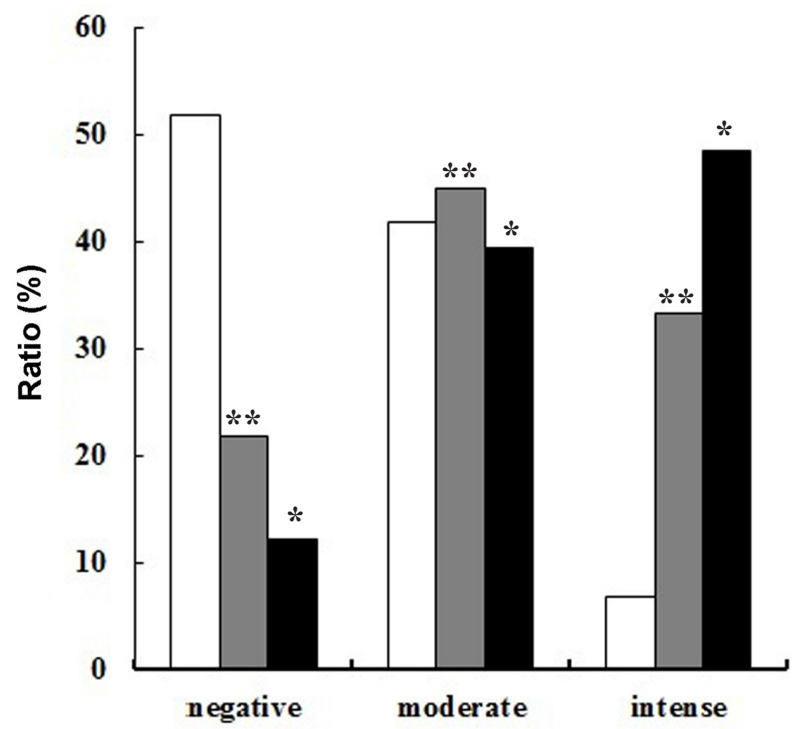

$\square$ Adjacent normal mucosa

口Laryngeal carcinoma

- Metastatic lymph nodes

Figure 6. Expression of moesin in laryngeal squamous cell carcinoma and cervical metastatic lymph nodes by immunohistochemical staining. $* * \mathrm{P}<0.01$ laryngeal carcinoma $v s$ adjacent normal mucosa. $* \mathrm{P}<0.01$ laryngeal carcinoma $v s$ metastatic lymph nodes.

\begin{tabular}{|c|c|c|c|c|c|c|c|c|}
\hline \multirow[t]{2}{*}{ Characteristics } & \multirow[t]{2}{*}{$\mathrm{P}$} & \multicolumn{3}{|c|}{ Ezrin [N (\%)] } & \multirow[t]{2}{*}{$\mathrm{P}$} & \multicolumn{3}{|c|}{ Moesin [N (\%)] } \\
\hline & & Negative & Moderate & Intense & & Negative & Moderate & Intense \\
\hline \multicolumn{9}{|l|}{ Gender } \\
\hline Male & $>0.05$ & $12(26.7)$ & $14(31.1)$ & $19(42.2)$ & $>0.05$ & $9(20.0)$ & $12(26.7)$ & $24(53.3)$ \\
\hline Female & & $3(0.2)$ & $4(26.7)$ & $8(53.3)$ & & $4(26.7)$ & $5(33.3)$ & $6(40.0)$ \\
\hline \multicolumn{9}{|l|}{ Smoking status } \\
\hline No & $>0.05$ & $5(38.5)$ & $2(15.4)$ & $6(46.1)$ & $>0.05$ & $1(7.7)$ & $4(30.8)$ & $8(61.5)$ \\
\hline Yes & & $10(21.3)$ & $12(25.5)$ & $25(53.2)$ & & $12(25.5)$ & $13(27.7)$ & $22(46.8)$ \\
\hline \multicolumn{9}{|l|}{ Age (years) } \\
\hline$<60$ & $>0.05$ & $8(25.0)$ & $6(18.8)$ & $18(56.2)$ & $>0.05$ & $6(18.8)$ & $11(34.4)$ & $15(46.8)$ \\
\hline$\geq 60$ & & $7(25.0)$ & $4(14.3)$ & $17(64.3)$ & & $7(25.0)$ & $5(17.9)$ & $16(57.1)$ \\
\hline \multicolumn{9}{|l|}{ Clinical Stage } \\
\hline $\mathrm{I}+\mathrm{II}$ & $>0.05$ & $8(50.0)$ & $3(18.8)$ & $5(31.2)$ & $<0.05^{*}$ & $6(37.5)$ & $4(25.0)$ & $6(37.5)$ \\
\hline $\mathrm{III}+\mathrm{IV}$ & & $7(15.9)$ & $9(24.3)$ & $28(75.7)$ & & $7(15.2)$ & $13(28.2)$ & $26(59.1)$ \\
\hline \multicolumn{9}{|l|}{ Primary tumor } \\
\hline $\mathrm{T} 1+\mathrm{T} 2$ & $<0.05^{*}$ & $10(43.5)$ & $6(26.1)$ & $7(30.4)$ & $<0.05^{*}$ & $9(39.1)$ & $6(26.1)$ & $8(34.8)$ \\
\hline $\mathrm{T} 3+\mathrm{T} 4$ & & $5(13.5)$ & $8(21.6)$ & $24(64.9)$ & & $4(10.8)$ & $10(27.0)$ & $23(62.2)$ \\
\hline \multicolumn{9}{|c|}{ Cervical lymphonode metastasis } \\
\hline Negative & $<0.05^{*}$ & $11(40.8)$ & $6(22.2)$ & $10(37.0)$ & $<0.05^{*}$ & $10(37.0)$ & $5(18.5)$ & $12(44.5)$ \\
\hline Positive & & $4(12.1)$ & $9(27.3)$ & $20(60.6)$ & & $3(9.1)$ & $10(30.3)$ & $20(60.6)$ \\
\hline \multicolumn{9}{|c|}{ Histologic differentiation } \\
\hline High & $>0.05$ & $6(27.3)$ & $4(18.2)$ & $12(54.5)$ & $>0.05$ & $8(36.4)$ & $5(22.7)$ & $9(40.9)$ \\
\hline Low-moderate & & $9(13.2)$ & $3(0.08)$ & $26(68.4)$ & & $5(13.2)$ & $9(23.7)$ & $24(63.1)$ \\
\hline
\end{tabular}

*The expression was significantly related to the clinical characteristics.

\section{Correlation of ezrin and moesin expression with overall survival}

As shown in Figures 7 and 8, there was a significant difference in overall survival time among the ezrin/moesin negative, moderate, and intense groups $(\mathrm{P}<0.001, \mathrm{P}<0.05)$. Patients with negative ezrin and moesin expression had a significantly longer overall survival time. 


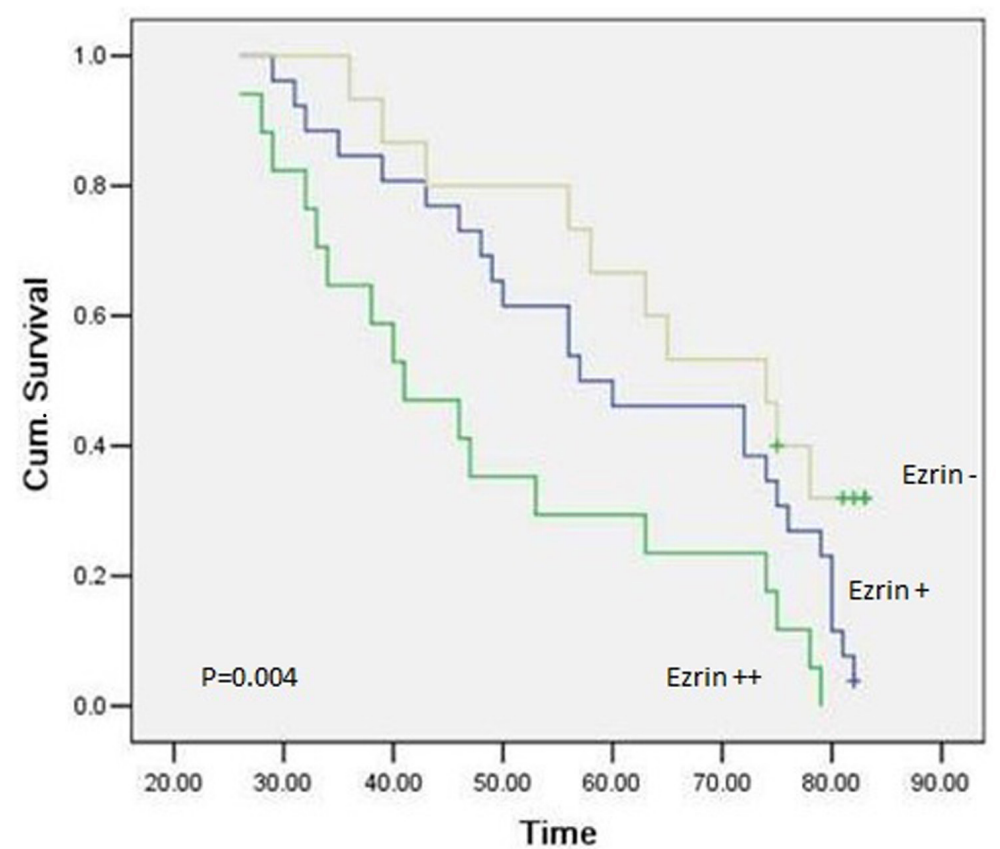

Figure 7. Relationship between expression of ezrin and overall survival time of laryngeal squamous cell carcinoma patients.

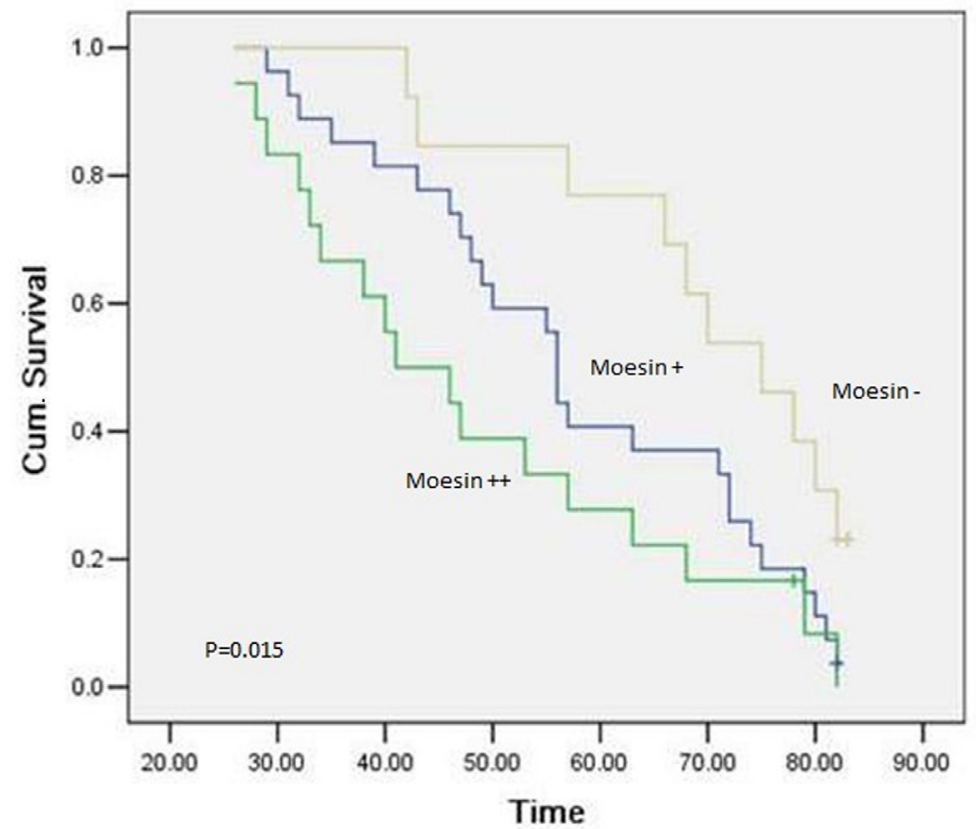

Figure 8. Relationship between expression of moesin and overall survival time of laryngeal squamous cell carcinoma patients. 


\section{DISCUSSION}

LSCC comprises the vast majority of laryngeal malignancies. Development of LSCC is a complex and multistep process. Tobacco use and alcohol consumption are regarded as the main risk factors. Another risk factor is human papillomavirus (HPV). A large number of genes involved in cell growth, death, and differentiation have a close relationship with the pathogenesis of LSCC. Current goals in the management of LSCC include improving survival, controlling the disease, and preserving voice, speech, and breathing functions. However, some advanced LSCC patients show high modality and recurrent and metastatic rates. Identification of metastatic signatures and molecular markers is necessary for developing novel prevention and treatment strategies for improving the survival and the quality of life in LSCC.

Tumor metastasis is an important factor affecting mortality rate. In LSCC, the most common metastatic pathway is through the cervical lymph nodes. Moreover, neck metastasis remains the first cause of treatment failure and death in LSCC (Shah and Patel, 2003). The invasion and metastasis of the tumor require basal membrane invasion by the cells, their intravasation in blood or lymph vessels, and their extravasation to reach and grow in distant tissues. At each step, cells undergo morphological changes driven by the cortical actin of the cytoskeleton. Proteins of the ezrin, radixin, and moesin (ERM) family provide a regulated linkage between the plasma membrane and the actin cytoskeleton. They are involved in determining cell shape, membrane organization, cell polarization, migration, and division, and they participate in a variety of signaling pathways (Lallemand and Arpin, 2010).

Ezrin, a member of the ERM family of proteins, is a key signaling molecule that is well-documented to be involved in a wide variety of cellular processes such as cell adhesion, cell survival, cell motility, and signal transduction (Bretscher et al., 2002; Gautreau et al., 2002; Saotome et al., 2004; Srivastava et al., 2005), all of which are important during tumor development and progression. Ezrin is associated with malignant progression and metastasis in a variety of human malignancies (Chen et al., 2001; Weng et al., 2005; Sarrió et al., 2006; Deng et al., 2007; Mhawech-Fauceglia et al., 2007; Elzagheid et al., 2008; Xie et al., 2009; Morales et al., 2010; Wang et al., 2011). Ezrin shows high expression in epithelial cell resource tumors, such as esophageal squamous cell carcinoma (ESCC) (Xie et al., 2009), nasopharyngeal carcinoma (Wang et al., 2011), colorectal cancer (Elzagheid et al., 2008), and ovarian epithelial carcinoma (Mhawech-Fauceglia et al., 2007), which predicts poor prognosis in these tumors. Our results indicated that $75.0 \%(45 / 60)$ of LSCC and $84.8 \%(28 / 33)$ of metastatic lymph nodes showed increased expression of ezrin. The high expression of ezrin was significantly correlated with cervical lymph node metastasis. These data are concomitant with the results of previous studies. Our results also confirmed that ezrin is related to advance clinical stage (I-II) and T stages (III-IV). These data suggest a key role of ezrin in LSCC progression and metastasis. High expression of ezrin was related to poor prognosis of head and neck squamous cell carcinoma (Mhawech-Fauceglia et al., 2007). Although the larynx is considered to be a site in the head and neck, LSCC has several peculiarities of clinical and molecular nature. The evaluation of ezrin in the metastasis and prognosis of LSCC has not been widely examined. Our study confirmed that increased ezrin expression was associated with advanced neck metastasis and poor prognosis. However, the exact mechanism has not been elucidated. Ezrin is involved in L1 (cell-neural adhesion 
molecule-mediated activation of nuclear factor kappa B signaling, which is a major route of progression in colorectal cancer (Gavert et al., 2010). Ezrin may influence the growth and invasiveness of ESCC cells through the mitogen-activated protein kinase and transforming growth factor- $\beta$ pathways or by affecting the expression of certain cell proliferation- or invasiveness-related genes, such as $A T F 3, C T G F$, or CYR61 (Xie et al., 2009). In human gastric carcinoma SGC-7901 cells, ezrin, radixin, or moesin were knocked down by small interfering RNA, which reduced cell migration and invasion by upregulating expression of E-cadherin (Ou-Yang et al., 2011). Therefore, ezrin may contribute to tumor metastasis and invasion through diverse complex mechanisms.

Moesin (membrane-organizing extension spike protein) is also a member of the ERM family. There is strong evidence that moesin plays a major role in cell functions, particularly in polarity and cortical actin congregation (Miller, 2003; Pilot et al., 2006). Moesin participates in adherent junction stability and has been implicated in vesicular trafficking and apical remodeling (Hughes and Fehon, 2007); both are key processes in carcinogenesis. Moesin expression has been associated with papillary thyroid carcinomas (Brown et al., 2006), oral squamous cell carcinomas (Kobayashi et al., 2004), basal breast carcinoma (Charafe-Jauffret et al., 2007), pancreatic cancer (Abiatari et al., 2010), colorectal carcinoma (Kim et al., 2012), and prostatic adenocarcinoma (Bartholow et al., 2011). In pancreatic adenocarcinoma, moesin-positive cases have been associated with shorter survival times than moesin-negative cases (Abiatari et al., 2010), with moesin-positive tumors showing higher histopathological grades and perineural and lymphovascular invasion rates (Torer et al., 2007). Our results indicated that $78.3 \%(47 / 60)$ of LSCC and $87.9 \%$ (29/33) of metastatic lymph nodes expressed high levels of moesin. The high expression of moesin was significantly correlated with cervical lymph nodes metastasis. Our results also confirmed that moesin was related to $\mathrm{T}$ stages (I-II), but not related to advanced clinical stages (III-IV). These data suggest an important role of moesin in LSCC progression and metastasis. Furthermore, moesin-positive cases have shorter survival times than moesinnegative cases.

Both ezrin and moesin belong to the ERM protein family. Conformational changes induced by phosphorylation activate these proteins (Bretscher et al., 1997), which bind actin and cell-type-dependent transmembrane proteins, such as CD44, CD43, and several I-CAMs (Tsukita et al., 1997), and are thus involved in the pathogenesis of LSCC. Recent studies have clearly indicated that ERMs regulate membrane-associated signaling pathways. ERMs act as cytoplasmic signaling scaffolds, for example, by acting as A-kinase anchoring proteins (Neisch and Fehon, 2011). Moreover, ERM members interact with Srcproteins in adhesion-mediated signaling (Srivastava et al., 2005). In our study, ezrin and moesin showed similar expression in LSCC. Because of the biological relevance of their functions, the clinical impact of their expression, and their association with survival time, ezrin and moesin may represent prognostic factors and new therapeutic targets for LSCC.

\section{ACKNOWLEDGMENTS}

We thank Dr. Zhang Lei for advice and assistance on the immunohistochemical experiments. Research supported by the Natural Science Foundation of HeiLongJiang Province in China (\#D200824). 


\section{REFERENCES}

Abiatari I, Esposito I, Oliveira TD, Felix K, et al. (2010). Moesin-dependent cytoskeleton remodelling is associated with an anaplastic phenotype of pancreatic cancer. J. Cell Mol. Med. 14: 1166-1179.

Bartholow TL, Chandran UR, Becich MJ and Parwani AV (2011). Immunohistochemical staining of radixin and moesin in prostatic adenocarcinoma. BMC Clin. Pathol. 11: 1.

Bretscher A, Reczek D and Berryman M (1997). Ezrin: a protein requiring conformational activation to link microfilaments to the plasma membrane in the assembly of cell surface structures. J. Cell Sci. 110 (Pt 24): 3011-3018.

Bretscher A, Edwards K and Fehon RG (2002). ERM proteins and merlin: integrators at the cell cortex. Nat. Rev. Mol. Cell Biol. 3: 586-599.

Brown LM, Helmke SM, Hunsucker SW, Netea-Maier RT, et al. (2006). Quantitative and qualitative differences in protein expression between papillary thyroid carcinoma and normal thyroid tissue. Mol. Carcinog. 45: 613-626.

Charafe-Jauffret E, Monville F, Bertucci F, Esterni B, et al. (2007). Moesin expression is a marker of basal breast carcinomas. Int. J. Cancer 121: 1779-1785.

Chen Z, Fadiel A, Feng Y, Ohtani K, et al. (2001). Ovarian epithelial carcinoma tyrosine phosphorylation, cell proliferation, and ezrin translocation are stimulated by interleukin lalpha and epidermal growth factor. Cancer 92: 3068-3075.

Deng X, Tannehill-Gregg SH, Nadella MV, He G, et al. (2007). Parathyroid hormone-related protein and ezrin are upregulated in human lung cancer bone metastases. Clin. Exp. Metastasis 24: 107-119.

Elzagheid A, Korkeila E, Bendardaf R, Buhmeida A, et al. (2008). Intense cytoplasmic ezrin immunoreactivity predicts poor survival in colorectal cancer. Hum. Pathol. 39: 1737-1743.

Gautreau A, Louvard D and Arpin M (2002). ERM proteins and NF2 tumor suppressor: the Yin and Yang of cortical actin organization and cell growth signaling. Curr. Opin. Cell Biol. 14: 104-109.

Gavert N, Ben-Shmuel A, Lemmon V, Brabletz T, et al. (2010). Nuclear factor-kappaB signaling and ezrin are essential for L1-mediated metastasis of colon cancer cells. J. Cell Sci. 123: 2135-2143.

Hughes SC and Fehon RG (2007). Understanding ERM proteins - the awesome power of genetics finally brought to bear. Curr. Opin. Cell Biol. 19: 51-56.

Kim CY, Jung WY, Lee HJ, Kim HK, et al. (2012). Proteomic analysis reveals overexpression of moesin and cytokeratin 17 proteins in colorectal carcinoma. Oncol. Rep. 27: 608-620.

Kobayashi H, Sagara J, Kurita H, Morifuji M, et al. (2004). Clinical significance of cellular distribution of moesin in patients with oral squamous cell carcinoma. Clin. Cancer Res. 10: 572-580.

Lallemand D and Arpin M (2010). Moesin/ezrin: a specific role in cell metastasis? Pigment Cell Melanoma Res. 23: 6-7.

Mathew J, Hines JE, Obafunwa JO, Burr AW, et al. (1996). CD44 is expressed in hepatocellular carcinomas showing vascular invasion. J. Pathol. 179: 74-79.

Mhawech-Fauceglia P, Dulguerov P, Beck A, Bonet M, et al. (2007). Value of ezrin, maspin and nm23-H1 protein expressions in predicting outcome of patients with head and neck squamous-cell carcinoma treated with radical radiotherapy. J. Clin. Pathol. 60: 185-189.

Miller KG (2003). A role for moesin in polarity. Trends Cell Biol. 13: 165-168.

Morales FC, Molina JR, Hayashi Y and Georgescu MM (2010). Overexpression of ezrin inactivates NF2 tumor suppressor in glioblastoma. Neuro Oncol. 12: 528-539.

Neisch AL and Fehon RG (2011). Ezrin, Radixin and Moesin: key regulators of membrane-cortex interactions and signaling. Curr. Opin. Cell Biol. 23: 377-382.

Ou-Yang M, Liu HR, Zhang Y, Zhu X, et al. (2011). ERM stable knockdown by siRNA reduced in vitro migration and invasion of human SGC-7901 cells. Biochimie 93: 954-961.

Pilot F, Philippe JM, Lemmers C and Lecuit T (2006). Spatial control of actin organization at adherens junctions by a synaptotagmin-like protein Btsz. Nature 442: 580-584.

Saotome I, Curto M and McClatchey AI (2004). Ezrin is essential for epithelial organization and villus morphogenesis in the developing intestine. Dev. Cell 6: 855-864.

Sarrió D, Rodríguez-Pinilla SM, Dotor A, Calero F, et al. (2006). Abnormal ezrin localization is associated with clinicopathological features in invasive breast carcinomas. Breast Cancer Res. Treat. 98: 71-79.

Shah JP and Patel KJ (2003). Head and Neck Surgery and Oncology. 3rd edn. Mosby, Edinburgh.

Srivastava J, Elliott BE, Louvard D and Arpin M (2005). Src-dependent ezrin phosphorylation in adhesion-mediated signaling. Mol. Biol. Cell 16: 1481-1490.

Torer N, Kayaselcuk F, Nursal TZ, Yildirim S, et al. (2007). Adhesion molecules as prognostic markers in pancreatic adenocarcinoma. J. Surg. Oncol. 96: 419-423.

Tsukita S, Yonemura S and Tsukita S (1997). ERM proteins: head-to-tail regulation of actin-plasma membrane interaction. 
Trends Biochem. Sci. 22: 53-58.

Vaheri A, Carpen O, Heiska L, Helander TS, et al. (1997). The ezrin protein family: membrane-cytoskeleton interactions and disease associations. Curr. Opin. Cell Biol. 9: 659-666.

Wang L, Lin GN, Jiang XL and Lu Y (2011). Expression of ezrin correlates with poor prognosis of nasopharyngeal carcinoma. Tumour. Biol. 32: 707-712.

Weng WH, Ahlén J, Aström K, Lui WO, et al. (2005). Prognostic impact of immunohistochemical expression of ezrin in highly malignant soft tissue sarcomas. Clin. Cancer Res. 11: 6198-6204.

Xie JJ, Xu LY, Xie YM, Zhang HH, et al. (2009). Roles of ezrin in the growth and invasiveness of esophageal squamous carcinoma cells. Int. J. Cancer 124: 2549-2558. 